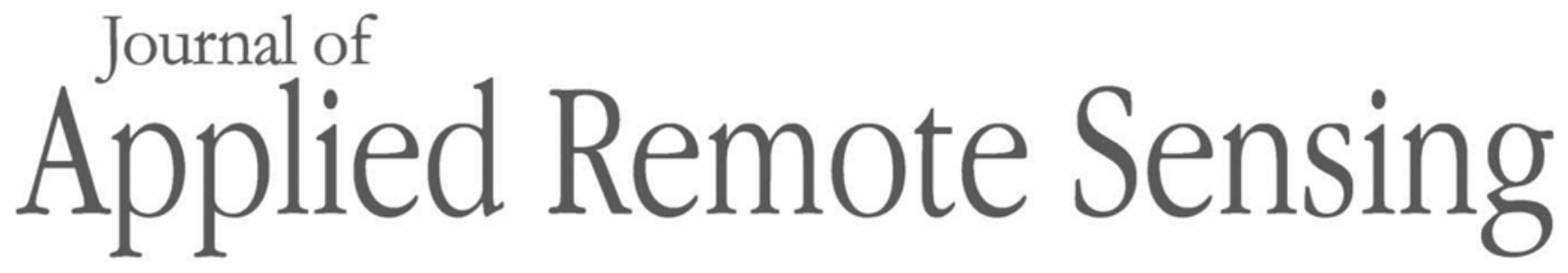

RemoteSensing.SPIEDigitalLibrary.org

\title{
Effects of land cover change on evapotranspiration in the Yellow River Delta analyzed with the SEBAL model
}

\author{
Jicai Ning \\ Zhiqiang Gao \\ Fuxiang $\mathrm{Xu}$
}




\title{
Effects of land cover change on evapotranspiration in the Yellow River Delta analyzed with the SEBAL model
}

\author{
Jicai Ning,* Zhiqiang Gao, and Fuxiang Xu \\ Yantai Institute of Coastal Zone Research, Chinese Academy of Sciences, \\ No. 17, Chunhui Road, Yantai 264003, China
}

\begin{abstract}
This study investigated the associations between land cover changes and evapotranspiration (ET) in the Yellow River Delta during the last 30 years using Landsat imagery. The result showed that the Delta region experienced a distinct increase in area due to sea-land interaction and sediment deposition, accompanied by substantial change in land cover fractions. From 1986 to 2015, 35.48\% of land cover changed, mainly due to a transformation into salterns and culture ponds from other land cover types. In general, land cover was converted from less developed into highly developed types. The monowindow algorithm for retrieval of land surface temperature (LST) and the SEBAL model were used to explore the effects of land cover changes on regional ET. The results indicated that the average relative error of daily ET was $9.46 \%$, and there was a significant linear correlation $\left(R^{2} \geq 0.959, p<0.001\right)$ between ET and LST. Relationships existed between LST, ET, fractional vegetation cover, and other relevant vegetation indices, and there were positive and negative correlations between different threshold ranges. During the study period, the transformation of large areas of different land cover types into salterns and culture ponds led to an average increase of $1.43 \mathrm{~mm}$ in daily ET. (c) 2017 Society of Photo-Optical Instrumentation Engineers (SPIE) [DOI: 10.1117/1.JRS.11.016009]
\end{abstract}

Keywords: SEBAL; evapotranspiration; land surface temperature; monowindow algorithm; Yellow River Delta.

Paper 16670 received Sep. 11, 2016; accepted for publication Dec. 21, 2016; published online Jan. 12, 2017.

\section{Introduction}

Research on climate change and water demand has increased over the past years because of dramatic environmental changes. One of the long-term solutions lies in understanding of how water use efficiency can be improved to reduce wastage. ${ }^{1}$ Quantitative predictions of regional water balances, management of water resources, irrigation scheduling, and climate and weather prediction require accurate quantification of evapotranspiration (ET) ${ }^{2-4}$ As an essential component of the hydrologic cycle, ET drives energy and water exchanges between the hydrosphere, atmosphere, and biosphere. ${ }^{5-7}$ ET is one of the fundamental parameters of the hydrologic cycle at all scales and is influenced by many factors, such as air temperature, soil moisture, and vegetation type. ${ }^{7,8}$ Accurate observation and estimation of ET are extremely important to increase our understanding of global climate change, land-atmosphere interactions, water cycle, and ecological studies. ${ }^{9-11}$ Development of remote sensing technology has made it possible to estimate land surface ET at the regional or basin scale. ${ }^{12}$ Bastiaanssen et al. ${ }^{13,14}$ developed the Surface Energy Balance Algorithm for Land (SEBAL), a remote sensing model that maps ET, biomass growth, water deficit, and soil moisture. Recent advances in retrieval algorithms and satellite remote sensing technology have enabled large-scale mapping of ET. ${ }^{15,16}$ Main single-source surface energy balance (SEB) models include the SEB model, ${ }^{17}$ the simplified surface energy balance index, ${ }^{18}$ the operational simplified surface energy balance model (SSEBop), ${ }^{19}$ the SEBAL, ${ }^{14,20}$ and its variant "mapping ET at high resolution with internalized calibration." 21 The SEBAL model is based on the SEB equation and has been used widely in the United States,

*Address all correspondence to: Jicai Ning, E-mail: jcning@yic.ac.cn

$1931-3195 / 2017 / \$ 25.00$ (C) 2017 SPIE

Journal of Applied Remote Sensing

016009-1

Jan-Mar 2017 • Vol. 11(1) 
Ning, Gao, and Xu: Effects of land cover change on evapotranspiration in the Yellow River...

Spain, Pakistan, Egypt, Sri Lanka, Turkey, China, and other countries with different climatic conditions. ${ }^{22-24}$ Using the SEBAL algorithm, Hafeez et al. ${ }^{25}$ calculated ET of the Pumapanga river area in the Philippines and obtained good results based on MODIS data.

The Yellow River Delta (YRD) has received increasing attention from scientists, engineers, and environmental planners, because of its critical role in wildlife protection, energy production, and agriculture ${ }^{26}$ Like many of the large deltas around the world ${ }^{27,28}$ the YRD is facing increasing risks of degradation due to anthropogenic and natural forces. ${ }^{29-32}$ With the expansion of reclamation activities, natural systems, especially wetland ecosystems, in the YRD area have been suffering from severe disturbances in recent years. ${ }^{33}$ Population growth, oil and gas extraction, and agricultural development have placed enormous demands on the land and water resources and modified the delta's natural geologic, hydrologic, and ecologic systems. ${ }^{34}$ ET represents a major link in the water cycle and affects the water exchange between the land surface and the atmosphere. Changes in ET caused by natural or anthropogenic factors should be investigated in detail for the YRD, which has a unique water balance that is different from that of other land surfaces.

The objective of this article is to examine how ET responded to changes in land cover in the YRD over the past 30 years based on a map of the ET distribution retrieved using the SEBAL model.

\section{Material and Methods}

\subsection{Study Area}

Located on the western coast of the Bohai Sea, the study area $\left(37^{\circ} 01^{\prime} \mathrm{N}\right.$ to $38^{\circ} 11^{\prime} \mathrm{N}, 118^{\circ} 04^{\prime} \mathrm{E}$ to $118^{\circ} 21^{\prime} \mathrm{E}$ ) encompasses the largest and youngest coastal wetland ecosystem in China, with a total area of about $11473 \mathrm{~km}^{2}$ in 2015 (Fig. 1). The elevation in our study area ranges from 0 to $45 \mathrm{~m}$ above sea level. The climate in this area is controlled by East Asian monsoon systems. Summers are warm and wet, while winters are cold and dry. The average annual temperature is $12.1^{\circ} \mathrm{C}$, with monthly means ranging from a minimum of $-1.3^{\circ} \mathrm{C}$ in December to a maximum of $27.7^{\circ} \mathrm{C}$ in August. The average annual precipitation is $552 \mathrm{~mm}$, of which $70 \%$ occurs during the summer. The average annual pan evaporation is $1962 \mathrm{~mm} .{ }^{33}$ The delta is a highly dynamic area, which has seen rapid urban and industrial development. ${ }^{35}$ With the acceleration of economic development and urbanization, the demand for land reclamation activities, such as port construction, construction of tidal embankments, aquaculture, and road construction, has expanded continuously. During the past three decades, saline-alkali land, beach land, and wetlands in coastal

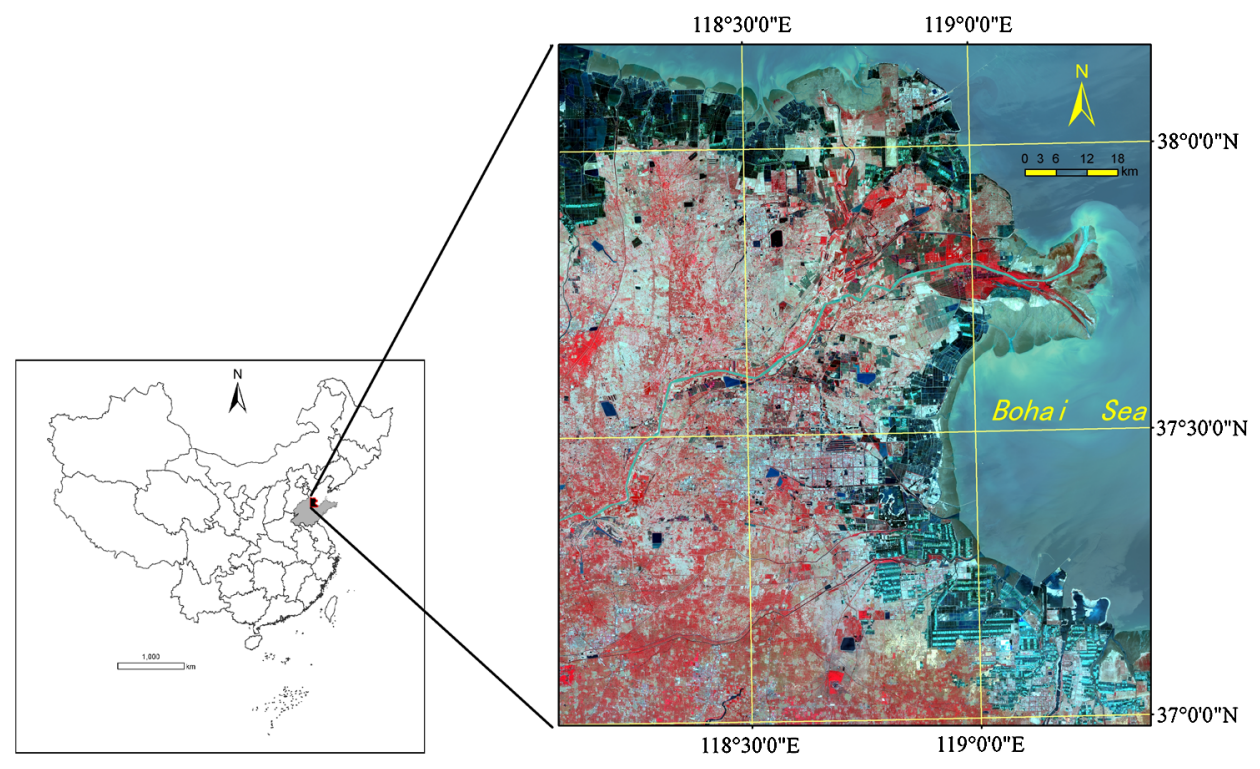

Fig. 1 Location of YRD (Standard pseudo-color Landsat image, June 5, 2015). 
Ning, Gao, and Xu: Effects of land cover change on evapotranspiration in the Yellow River...

areas have been reclaimed as salterns, culture ponds, and agricultural farmland at a fast pace. This has greatly increased environmental pressures on the vulnerable YRD ecosystem.

Landsat images of the same day in different years were selected as the data source for a comparative study of ET and vegetation indexes in the YRD. To obtain better inversion results, images from the dry season were selected and combined with data of local meteorological conditions. We used Landsat 5 TM (June 5, 1986) and Landsat 8 OLI/TIRS (June 5, 2015) data (from the USGS). After examining data from the meteorological stations in the study area, it was determined that ET values for two consecutive days could be considered the same, due to similar weather conditions for those days. After atmospheric and radiometric correction to remove data noise ${ }^{36}$ the remote sensing data were used as basic source data for the retrieval of LST and ET. By combining classification methods and manual interpretation, the land cover data were extracted based on a new classification system. The classification criteria were adjusted based on the requirements for the analysis of ET reaction. The overall accuracy was greater than $95 \%$ as validated by field visits and historical data. Meteorological data, including temperature, wind speed, relative humidity, and precipitation, were obtained from 14 internal and peripheral meteorological stations from the China Meteorological Data Network. An inverse distance weighting interpolation method was used to obtain relevant meteorological raster data for the study area, based on the meteorological point data acquired from internal and surrounding observations. All data were georeferenced to a common UTM coordinate system (WGS 1984_UTM_Zone_50N) and resampled using a nearest neighbor algorithm with a pixel size of $30 \mathrm{~m} \times 30 \mathrm{~m}$.

The Landsat 8 image obtained on June 5, 2015 was geometrically corrected based on the Landsat 5 image of June 5, 1986. Band 6 of Landsat 5 and band 10 of Landsat 8 were chosen for thermal infrared temperature inversion. Qin's monowindow algorithm ${ }^{37}$ was adopted for the inversion calculation for determining the LST, and the SEBAL model was used to create a map of the daily ET distribution in the study area based on the inverted LST. Atmospheric correction of Landsat TM/ETM data should be carried out by combining a look-up table and dark-object method, in order to obtain accurate reflectance data. ${ }^{38-41}$

\subsection{Land Cover Information Extraction}

The spectral variability between ground objects represents a theoretical basis for analyses and interpretations of remote sensing images. The phenomenon related to an object composed of pixels with different spectral characteristics and different objects composed of pixels with the same spectral characteristics, in conjunction with the existence of mixed pixels can make it difficult to identify certain ground objects. ${ }^{42}$ In this study, land cover information was extracted based on the spectral characteristics of ground objects, taking into consideration the particular ecosystems of the YRD area. First, remote sensing images were visually interpreted, and a preliminary land use/land cover classification was performed based on the actual land use status. Next, a number of sampling points were selected for each land type to measure the multispectral band values, to determine a spectral region for different types of land covers, and to create spectral thresholds for different ground objects. Finally, a decision tree classification model was created based on the thresholds, and a preliminary land cover map was created for the research area. Based on the results of the automatic classification, blocks of land cover types had to be edited manually based on the regional characteristics of the river basin and coastal area. Historical landuse data and field survey data were used as reference data for the classification.

\subsection{Retrieval of Land Surface Temperature}

The development of the monowindow algorithm for LST retrieval from the thermal band data of Landsat TM/ETM is based on the premise that the at-satellite brightness temperature can be computed from the thermal band. According to the radiance transfer equation, Taylor's expansion to the Planck function has to be applied. Qin et al. ${ }^{37}$ derived an approximate expression for LST retrieval, suitable for the thermal bands of TM/ETM+ data by simplifying the relationship between radiance and brightness temperature using a linear regression, as expressed below: 
Ning, Gao, and Xu: Effects of land cover change on evapotranspiration in the Yellow River...

$$
T_{s}=\left\{a_{6}\left(1-C_{6}-D_{6}\right)+\left[b_{6}\left(1-C_{6}-D_{6}\right)+C_{6}+D_{6}\right] T_{6}-D_{6} T_{a}\right\} / C_{6},
$$

in which $T_{s}$ is the LST (K); $T_{6}$ is the brightness temperature (K) (band 6 for Landsat 5, band 10 for Landsat 8); $a_{6}$ and $b_{6}$ are the regression coefficients between $T_{6}$ and $C_{6}$; and $T_{\mathrm{a}}$ is the average effective mean atmospheric temperature $(\mathrm{K})$. In practice, the possible temperature range of LST is 0 to $70^{\circ} \mathrm{C}, a_{6}=-67.35535$ and $b_{6}=0.458608 . C_{6}$ and $D_{6}$ are coefficients defined as expressed below in Eqs. (2) and (3):

$$
\begin{gathered}
C_{6}=\varepsilon_{6} \tau_{6}, \\
D_{6}=\left(1-\tau_{6}\right)\left[1+\left(1-\varepsilon_{6}\right) \tau_{6}\right],
\end{gathered}
$$

where $\tau_{6}$ is the atmospheric transmittance (dimensionless) and $\varepsilon_{6}$ is the ground emissivity (dimensionless), both at band 6. $\tau_{6}$ can be approximated from the relative humidity and temperature data, ${ }^{37}$ and $\varepsilon_{6}$ can be derived from the relevant vegetation index. ${ }^{43}$

\subsection{Retrieval of Surface Flux and Evapotranspiration}

The SEBAL model, which is designed based on traditional surface heat balance equations, can integrate multisource and multisensor data to estimate land surface water and heat fluxes, employing the advantages of remote-sensing technologies. The equations are based on the theory that incoming net solar radiation drives all energy exchanges on the Earth's surface. The SEB equation is as follows: ${ }^{14}$

$$
\mathrm{LE}=R_{n}-G-H,
$$

where LE is the latent heat flux $\left(\mathrm{W} \mathrm{m}^{-2}\right) ; R_{n}$ is the net radiation $\left(\mathrm{W} \mathrm{m}^{-2}\right) ; G$ is the soil heat flux $\left(\mathrm{W} \mathrm{m}^{-2}\right)$; and $H$ is the sensible heat flux $\left(\mathrm{W} \mathrm{m}^{-2}\right)$. As one of the residual methods of the energy budget, the SEBAL model was developed based on the energy balance principle and aerodynamic turbulence theory.

In Eq. (4), the net radiation, which is the summation of soil heat flux, sensible heat flux, and latent heat flux, can be calculated based on the land surface radiation as follows:

$$
R_{n}=(1-\alpha) R_{\mathrm{s}} \downarrow+\varepsilon_{\mathrm{s}} \sigma\left(\varepsilon_{\mathrm{a}} T_{\mathrm{a}}^{4}-T_{\mathrm{s}}^{4}\right),
$$

where $R_{\mathrm{S}} \downarrow$ is the incident solar short-wave radiation, also known as the total solar radiation $\left(\mathrm{W} \mathrm{m}^{-2}\right) ; \alpha$ is the surface albedo (dimensionless); $\varepsilon_{\mathrm{s}}$ is the surface emissivity (dimensionless); $\sigma$ is the Stefan-Boltzmann constant $\left(5.6696 \times 10^{-8} \mathrm{~W} \mathrm{~m}^{-2} \mathrm{~K}^{-4}\right) ; T_{\mathrm{S}}$ is the LST $(\mathrm{K})$, retrieved from remote-sensing data; $T_{\mathrm{a}}$ is the air temperature $(K)$ of reference height $(Z 2)$; and $\varepsilon_{\mathrm{a}}$ is the atmospheric emissivity (dimensionless), which can be calculated by an empirical formula. ${ }^{8,28}$

Following the same logic as shown in the literature, the SEBAL model produces the instantaneous soil heat flux $G\left(\mathrm{~W} \mathrm{~m}^{-2}\right)$ that is defined as a function of surface albedo, vegetation index, and LST: ${ }^{29}$

$$
G=\left\{\frac{\left(T_{\mathrm{s}}-273.15\right)}{\alpha}\left(0.0038 \alpha+0.007 \alpha^{2}\right)\left[1-0.98(\mathrm{NDVI})^{4}\right]\right\} R_{n},
$$

in which NDVI is dimensionless. Morse et al. ${ }^{24}$ reported that clear, deep water areas can be considered as a large heat reservoir, if the evaporation is not excessive. Burba et al. ${ }^{44}$ suggested the equation $G_{\text {water }}=0.41 R_{n}-51$ based on a study of wetlands. The water body in the study area was situated between the clear water body and the wetland. Based on the research above, we used Eq. (6) to calculate the instantaneous heat flux in vegetated areas, and $G_{\text {water }}=0.5 R_{n}$ was used for water bodies. ${ }^{45}$ The sensible heat flux $(H)$ is the heat exchange between the surface and the planetary boundary layer, and can be expressed as follows: ${ }^{46}$

$$
H=\rho_{\mathrm{a}} c_{\mathrm{P}} \frac{\left(T_{\mathrm{s}}-T_{\mathrm{a}}\right)}{r_{\mathrm{ah}}}=\rho_{\mathrm{a}} c_{\mathrm{P}} \frac{d T}{r_{\mathrm{ah}}},
$$


Ning, Gao, and Xu: Effects of land cover change on evapotranspiration in the Yellow River...

where $\rho_{\mathrm{a}}$ is the air density $\left(\mathrm{kg} \mathrm{m}^{-3}\right) ; c_{\mathrm{P}}$ is the air heat capacity at constant pressure $\left[1004.07 \mathrm{~J}(\mathrm{~kg} \mathrm{~K})^{-1}\right]$; $d T$ is the temperature difference $(\mathrm{K})$ over the two heights of $Z 2$ and $Z 1$; and $r_{\mathrm{ah}}$ is the aerodynamic resistance $\left(\mathrm{m} \mathrm{s}^{-1}\right)$ between $Z 2$ and $Z 1 ; Z 1$ is the first reference height and $Z 2$ is the second reference height.

According to Eq. (7), there are two unknown parameters $\left(d T\right.$ and $\left.r_{\mathrm{ah}}\right) . r_{\mathrm{ah}}$ can be calculated using wind speed, and $d T$ can be obtained by a series of iterative processes. Gao et al. ${ }^{47}$ described the detailed calculations. The modified soil-adjusted vegetation index (MSAVI) combined with LST was chosen to determine the "hot" "cold" points automatically. For the classes of farmland, grassland, and bare land, pixels with a value of 0.1 MSVI and the largest LST values were designated "hot" points. The mean value of these pixels was considered a virtual "hot" point. The same method was used to determine the virtual "cold" point for the classes of farmland, forest, and wetland (0.8 MSVI combined with the minimum value of LST). Using the average value for several pixels avoided uncharacteristic results caused by a single pixel. An iterative procedure was used for the calculation of $H$ for each pixel to minimize discrepancies due to a small sample size, which is deemed an appropriate method for this study.

Finally, based on the energy balance equation, the instantaneous latent heat flux can be computed, as shown in Eq. (6). Then, instantaneous ET (mm) can be calculated as follows:

$$
\mathrm{ET}=60 \times 60 \times \frac{\mathrm{LE}}{\lambda}
$$

in which $\lambda=\left[2.501-0.00236\left(T_{\mathrm{a}}-273.15\right)\right] \times 10^{6}$.

The ET estimated by this remote-sensing-based method represents instantaneous conditions. To achieve the estimation of the daily ET, the instantaneous ET must be extended temporally, and several commonly used methods include the statistical empirical method, the sine relations method, and the evaporative fraction method. In this study, we followed the evaporative fraction method to extend the calculation from instantaneous ET to daily ET: ${ }^{48}$

$$
\mathrm{ET}_{24}=24 \times 60 \times 60 \times \Lambda_{24} \times \frac{R_{n 24}-G_{24}}{\lambda \cdot \rho_{w}} \times 10^{3},
$$

where $R_{n 24}$ is the $24 \mathrm{~h}$ net radiation $\left(\mathrm{W} \mathrm{m}^{-2}\right) ; \mathrm{G}$ is the $24-\mathrm{h}$ soil heat flux $\left(\mathrm{W} \mathrm{m}^{-2}\right) ; \rho_{w}$ is the density of water $\left(1.0 \times 103 \mathrm{~kg} \cdot \mathrm{m}^{-3}\right) ; \lambda$ is the latent heat of water vapor $\left\{\lambda=\left[2.501-0.00236\left(T_{s}-273.15\right)\right] \times 10^{6}, \mathrm{~J} \bullet \mathrm{Kg}^{-1}\right\} ; \Lambda_{24}$ is the 24-h average evaporative fraction, which is approximately equal to the instantaneous evaporative fraction $\Lambda$. $\Lambda$ can be calculated by

$$
\Lambda=\frac{\mathrm{LE}}{R_{n}-G},
$$

where LE, $R_{n}$, and $G$ are variables explained above.

Due to a lack of heat flux monitoring data for the study area, ET was validated by using regional ET data from weather stations.

\subsection{Calculation of Normalized Difference Vegetation Index and Fractional Vegetation Cover}

The normalized difference vegetation index (NDVI) is defined as

$$
\mathrm{NDVI}=\frac{\rho_{\text {nir }}-\rho_{\text {red }}}{\rho_{\text {nir }}+\rho_{\text {red }}}
$$

where $\rho_{\text {nir }}$ is the reflectance for the near infrared band (band 4 for Landsat 5, band 5 for Landsat 8) and $\rho_{\text {red }}$ is the reflectance for the red band (band 3 for Landsat 5, band 4 for Landsat 8).

Fractional vegetation cover (FVC) is an important biophysical parameter describing vegetation quality and reflecting ecosystem changes. It is also a controlling factor in transpiration, photosynthesis, and other terrestrial processes. The calculation of FVC is based on NDVI values, which may be calculated using spectral reflectance data. FVC was computed as expressed below: ${ }^{49}$ 
Ning, Gao, and Xu: Effects of land cover change on evapotranspiration in the Yellow River...

$$
\mathrm{FVC}=\frac{\mathrm{NDVI}-\mathrm{NDVImin}}{\mathrm{NDVI} \max -\mathrm{NDVI}} \times 100 \%
$$

where FVC is the fractional vegetation cover (\%); NDVI is the NDVI value at each pixel (dimensionless); NDVImax is the NDVI value that corresponds to $100 \%$ vegetation cover (dimensionless); and NDVImin is the NDVI of bare soil (dimensionless).

\section{Results and Analysis}

\subsection{Analysis of the Spatial-Temporal Pattern of Land Cover}

\subsubsection{Spatial distribution and change in land cover types}

Due to sea-land interaction and sediment deposition in river mouths, the area of salterns and culture ponds increased by $205.81 \mathrm{~km}^{2}$ from 1986 to 2015 (Fig. 2 and Table 1). The land cover types were divided into 10 classes, as shown in Table 1 . The total area was $11267.69 \mathrm{~km}^{2}$ in 1986, and farmland was the dominant land cover type (55.18\%). Compared to 1986, there were noticeable changes in land use and land cover types in 2015. The two land cover types with the largest increases were salterns and culture ponds, whose area increased by 1303.07 and $582.66 \mathrm{~km}^{2}$, respectively. The combined proportional area for both classes increased sharply from $2.51 \%$ to $18.90 \%$. The area of the built-up class also increased considerably by $394.98 \mathrm{~km}^{2}$. In contrast, the grassland and saline-alkali land area decreased sharply by $2273.57 \mathrm{~km}^{2}$. While estuarine deposition expanded, the beach area decreased by $185.92 \mathrm{~km}^{2}$ due to human activities.

For the combined land cover types, $3947.22 \mathrm{~km}^{2}$ changed from 1986 to 2015 , accounting for $35.03 \%$ of the total land area in 1986, meaning that more than one-third of the land cover changed over 30 years. A spatial comparison of the land cover types for different years showed that there were different causes for conversion for different types of land covers. Despite an increase in the gross area of farmland, almost $200 \mathrm{~km}^{2}$ were transformed into salterns and culture ponds. The increase in farmland area was caused mainly by the development and conversion of grassland and wetland. The grassland was converted not only into farmland, but into salterns and culture ponds as well. $193.94 \mathrm{~km}^{2}$ of grassland was converted into built-up areas. $67.50 \mathrm{~km}^{2}$ of wetland was converted into farmland, accounting for $23 \%$ of the total changed area. $30 \%$ of changed area was converted into salterns and culture ponds, while $14 \%$ and $1 \%$ were converted into water and saline-alkali land, respectively. The diversity of wetland conversion modes also demonstrated the fragility of wetland ecosystems. Saline-alkali fields were distributed mainly on
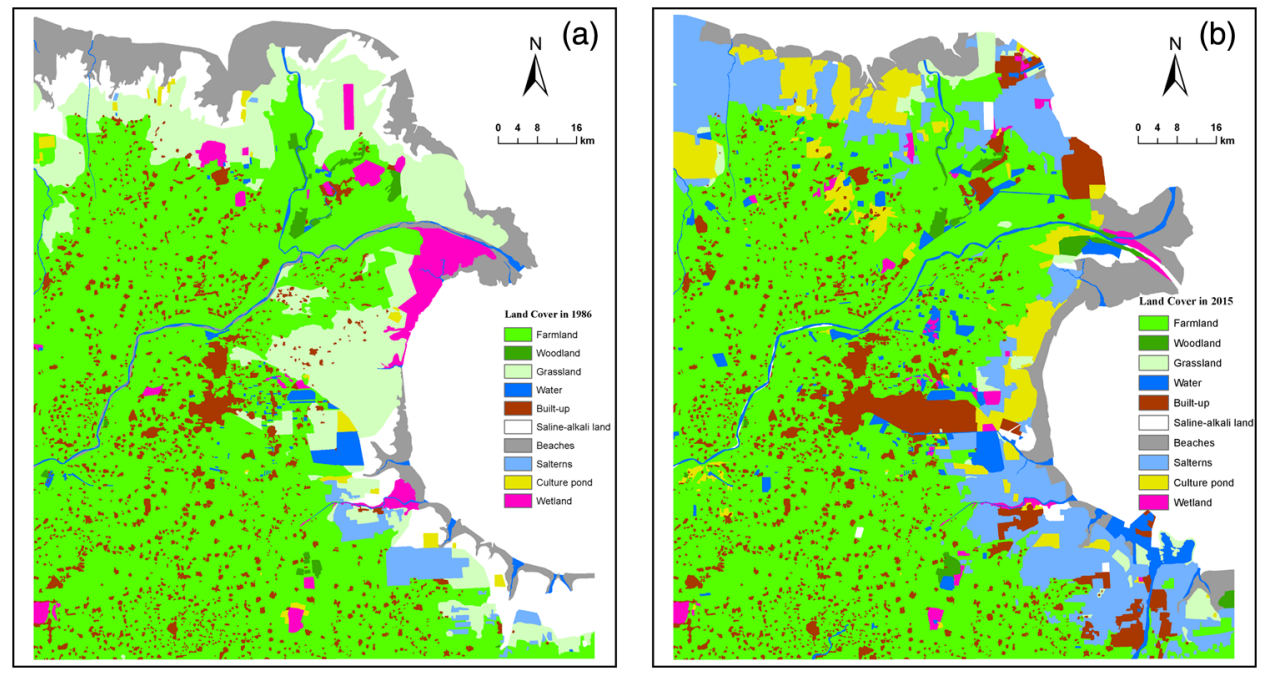

Fig. 2 Land-cover maps on June 5 in (a) 1986 and (b) 2015. 
Ning, Gao, and Xu: Effects of land cover change on evapotranspiration in the Yellow River...

Table 1 Area and percentages of land cover types.

\begin{tabular}{|c|c|c|c|c|}
\hline \multirow[b]{2}{*}{ Land cover type } & \multicolumn{2}{|c|}{1986} & \multicolumn{2}{|c|}{2015} \\
\hline & Area $\left(\mathrm{km}^{2}\right)$ & Percentage (\%) & Area $\left(\mathrm{km}^{2}\right)$ & Percentage (\%) \\
\hline Farmland & 6217.90 & 55.18 & 6434.64 & 56.08 \\
\hline Woodland & 65.91 & 0.58 & 97.43 & 0.85 \\
\hline Grassland & 1772.91 & 15.73 & 194.34 & 1.69 \\
\hline Water & 194.26 & 1.72 & 475.89 & 4.15 \\
\hline Built-up & 722.79 & 6.41 & 1117.77 & 10.27 \\
\hline Saline-alkali land & 771.79 & 6.85 & 76.79 & 0.67 \\
\hline Beaches & 906.25 & 8.04 & 720.34 & 6.28 \\
\hline Salterns & 209.41 & 1.86 & 1512.48 & 13.18 \\
\hline Culture Pond & 73.20 & 0.65 & 655.86 & 5.72 \\
\hline Wetland & 333.28 & 2.96 & 127.94 & 1.12 \\
\hline Total & 11267.691 & 100 & 11473.5 & 100 \\
\hline
\end{tabular}

the coast and were converted primarily into salterns, culture ponds, and farmland. Specifically, $409.93 \mathrm{~km}^{2}$ were converted into salterns, accounting for $55 \%$ of the total conversion area.

\subsubsection{Correlation analysis of land cover and fractional vegetation cover}

A map of FVC distribution was created based on Eqs. (11) and (12). Regions with a FVC value equal to or smaller than 0 were water areas. It was evident from the FVC maps for the different years that there was a significant increase in water area in 2015 (Fig. 3). Analysis of the land use change demonstrated that large areas of lower vegetation cover (saline-alkali land) changed into areas of higher vegetation cover of farmland and forest land. The construction of salterns and culture ponds greatly reduced the areal proportion of saline-alkali land. Overall, the vegetation cover increased due to improvement and utilization of saline alkali land from 1986 to 2015, and the average FVC value of vegetation-covered areas increased from $21.13 \%$ in 1986 to $33.91 \%$ in
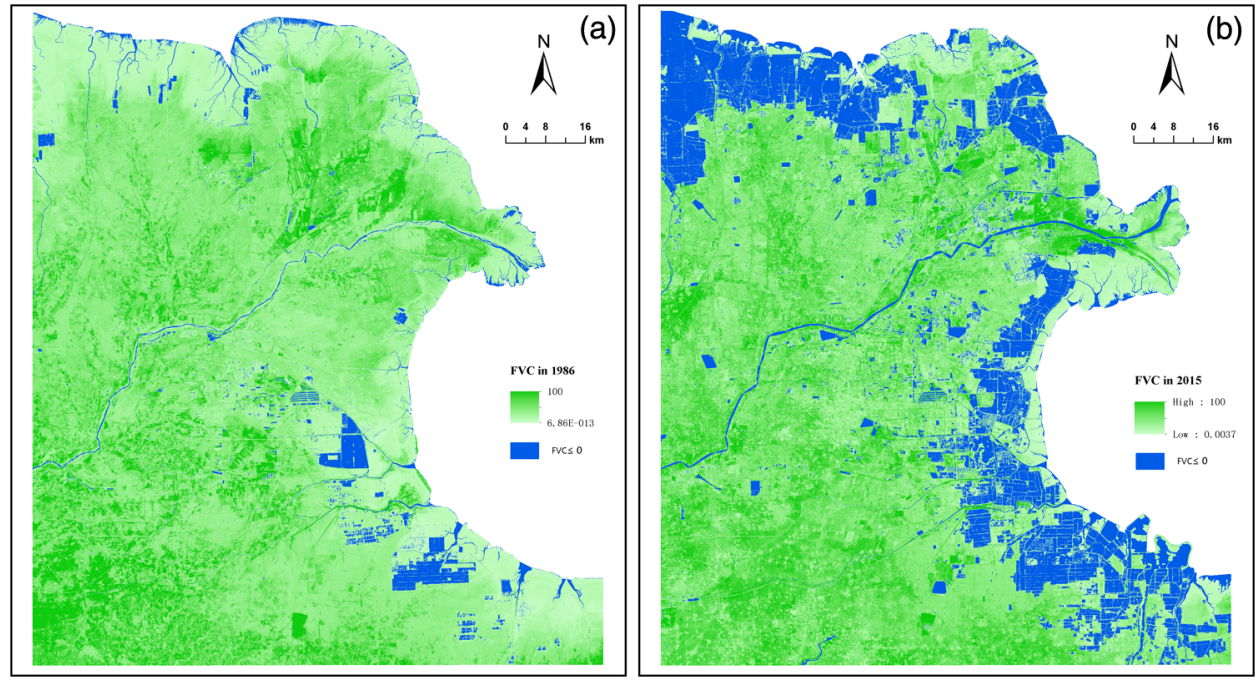

Fig. 3 FVC distribution maps in (a) 1986 and (b) 2015. 
Ning, Gao, and Xu: Effects of land cover change on evapotranspiration in the Yellow River...

2015. Among all land cover types, woodland had the highest FVC values, 51.94\% in 1986, and $55.59 \%$ in 2015 . Wetland and farmland areas also had more vegetation cover, while the salinealkali land, beaches, and salterns had less vegetation cover and lower FVC values. The beaches had the lowest FVC values due to sparse vegetation. FVC reflected the spatial distribution of the regional vegetation cover appropriately.

\subsection{Analysis of the Spatial-Temporal Pattern of Evapotranspiration}

Daily ET was determined using the SEBAL model (Fig. 4). It can be seen from the profile that the daily ET first decreases and then increases inward from the coast. This was closely related to the spatial distribution of land cover types. High ET values occurred in the salterns and culture ponds in the coastal region because of sufficient water sources. In the large farmland areas in the inland region, high vegetation cover contributed to high ET. Most of the transitional zones between the farmland and culture ponds were less developed grassland and saline-alkali land, therefore, the ET was low in these areas. Compared to 1986, 2015 saw an increase in ET, suggesting that with increasing development, the salterns and culture ponds increased in area, while the saline-alkali land cover decreased. As a result, the overall regional ET increased. It was concluded that land use changes affected the variation in ET.

Different land cover structures affected every aspect of ET, therefore, ET changed due to the difference in land cover type (Fig. 2). It was evident from Fig. 4 that ET was high for the water region, salterns, culture ponds, and beaches, and this was closely related to adequate water supply. By contrast, ET was low in the built-up region, saline-alkali land, and grassland, because most energy was lost through sensible heat exchange. Comparing ET values for different land cover types showed a similar pattern for each year, suggesting that daily ET was closely related to land cover type (Fig. 5). Nearly every land cover type had a higher daily ET in 2015 than in 1986. An analysis of the LST indicated that a higher LST in 2015 enhanced the heat exchange and thus increased the ET values.

\subsection{Analysis of Land Cover Effects on Evapotranspiration}

The analyses above indicated that there was a close correlation between LST and ET. We overlaid LST and ET distribution maps and developed a linear regression for LST and ET. LST was discretized in 1-deg intervals, and the average ET value for a certain temperature was calculated by determining the spatial overlap of the ET distribution map. A close, negative correlation existed between LST and ET (Fig. 6). The correlation coefficient was -0.9868 in 1986 and -0.9752 in 2015 .
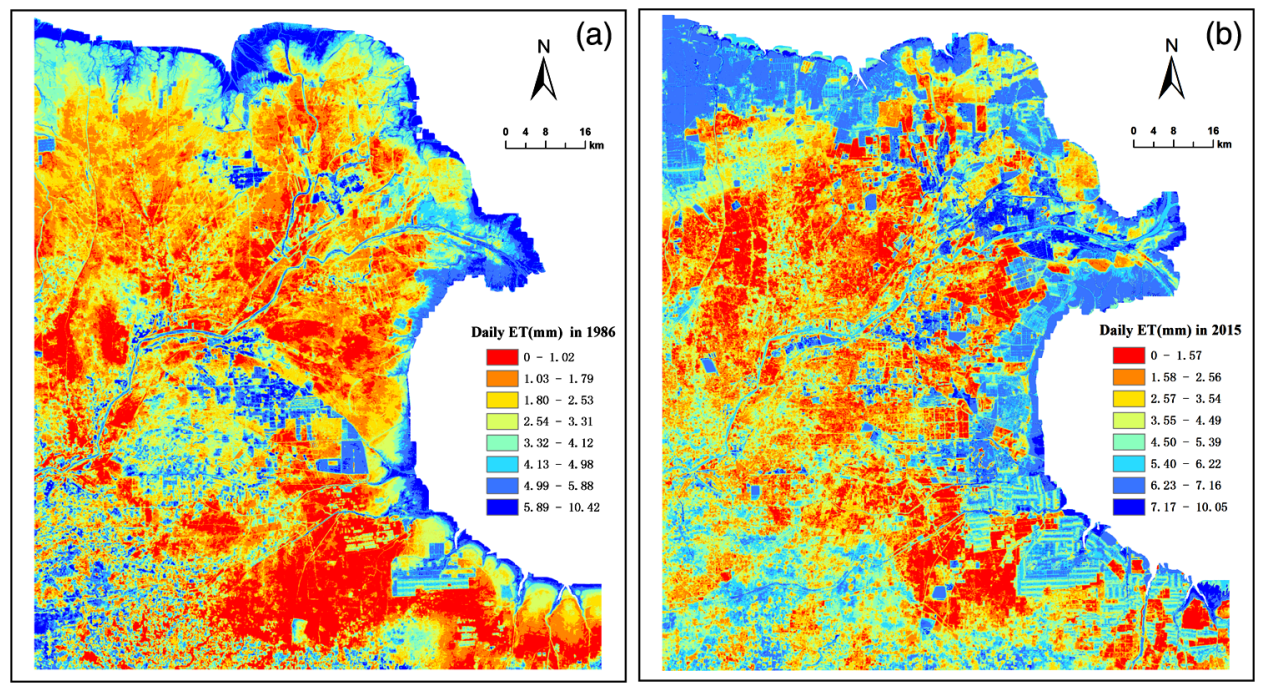

Fig. 4 Daily ET distribution maps on June 5 in (a) 1986 and (b) 2015. 
Ning, Gao, and Xu: Effects of land cover change on evapotranspiration in the Yellow River...

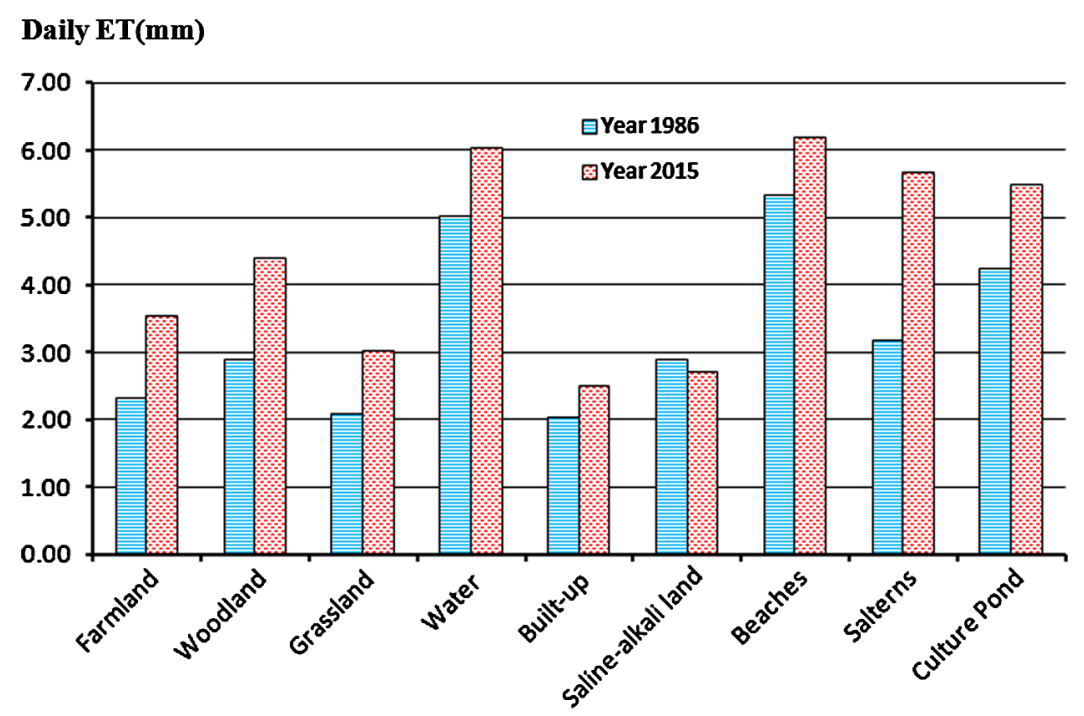

Land Cover

Fig. 5 Comparison of daily ET values for different land covers.

A linear solution to ET and LST for the 2 years can help derive their linear equations. These two equations had nearly the same slope and similar intercepts, and $R^{2}$ values were 0.9738 and 0.951 , respectively. A synthesis of the data for both years resulted in the following linear equation for LST and ET $(p=0.00018)$ :

$$
\mathrm{ET}=-0.2326 \mathrm{LST}+11.595 \quad\left(R^{2}=0.9588\right),
$$

where ET denotes daily ET (mm), and LST denotes land surface temperature $\left({ }^{\circ} \mathrm{C}\right)$. Equation (13) can be used for approximate calculation of daily ET if there is a lack of data for ET calculation, and LST values are available. Land cover status affects the distribution of LST and influences the spatial distribution of ET. We used FVC to research the relationship between ET and land cover types. We overlaid maps of ET distribution and FVC at $1 \%$ intervals, as shown in Fig. 7.

FVC was closely related to LST, as well as to daily ET (Fig. 4). An FVC value of $14 \%$ was the inflection point in 1986 (25\% in 2015). Daily ET and FVC were negatively correlated when FVC was between $1 \%$ and $14 \%$ in 1986 (1\% and 25\% in 2015), and the correlation coefficient was -0.99 in 1986 (-0.96 in 2015). Daily ET and FVC were positively correlated when FVC

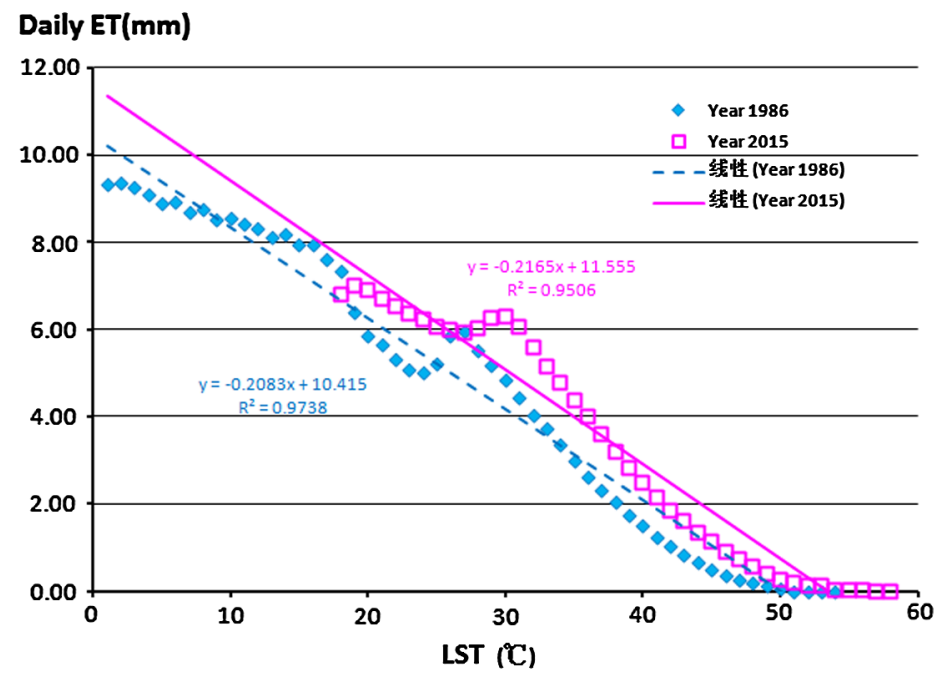

Fig. 6 Correlation between daily ET and LST. 
Ning, Gao, and Xu: Effects of land cover change on evapotranspiration in the Yellow River...

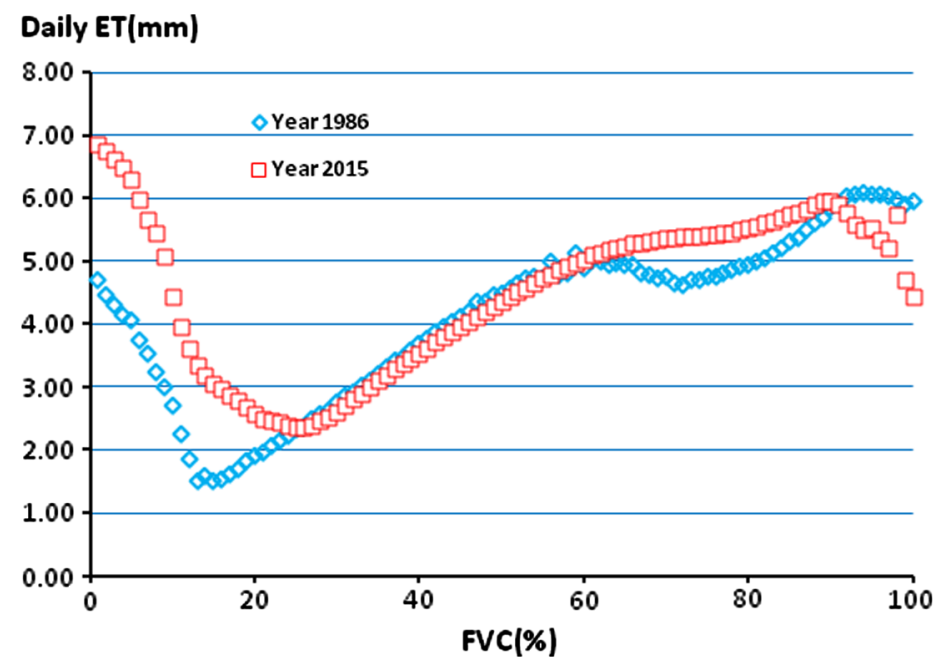

Fig. 7 Scatter plots between the mean daily ET and the FVC.

was between $14 \%$ and $94 \%$ in 1986 (26\% and $90 \%$ in 2015), and the correlation coefficient was 0.95 in 1986 (0.97 in 2015). When the FVC value exceeded 94\% in 2015, daily ET and FVC were negatively correlated.

It is easy to understand why areas with higher FVC values also had greater ET values. Comparison of the land cover maps in Fig. 2 with the FVC maps in Fig. 3 demonstrated that land cover types with FVC value $<14 \%$ based on the 1986 data (25\% in 2015) were mainly associated with bare land such as beach and saline-alkali lands close to water bodies. This pattern between evaporation and FVC obviously reflected the degree of soil exposure and neighborhood effects. Furthermore, denser vegetation growth is usually the result of increased moisture or greater use of fertilizer. The existence of mixed pixels aggravated the negative correlation between FVC and daily ET. After the inflection point, daily ET values began to increase along with the greater vegetation cover to result in higher ET. Generally, the increase in vegetation fraction led to a decrease in sensible heat, which consequently led to a decrease in the surface temperature and an increase in the latent heat flux and ET. Comparing Fig. 2 with Fig. 3 showed that the highest FVC values occurred for wetlands. In wetlands, the existence of vegetation would reduce the evaporation from the water surface, therefore when the FVC value reached a certain value (e.g., FVC above 90\% in 1986 and 94\% in 2015), the daily ET tended to decline, as shown in Fig. 7.

\section{Discussion}

Over nearly 30 years, considerable land cover change occurred in the YRD. Overall, transformation occurred primarily from less developed to highly developed land. Large changes in land cover inevitably affected the distribution and transformation of the regional SEB. Measurements of ET could not be obtained for our study of the YRD, and therefore, a comparison was conducted between water surface evaporation obtained by calculation and that measured at the meteorological station. The value measured in a small evaporating dish on June 5, 1986 was $9.5 \mathrm{~mm}$. According to the monthly conversion coefficient for the country of $0.6,{ }^{50}$ we determined that the mean evaporation from the water surfaces in the area was $5.7 \mathrm{~mm}$, while the mean inversion evaporation from the water bodies in the area was 5.00. The inversion accuracy was $87.75 \%$. On June 5, 2015, the average of mean evaporation from large evaporating dishes was $6.45 \mathrm{~mm}$, the mean evaporation from the water bodies obtained by inversion was 6.02 , and the inversion accuracy was $93.33 \%$. The average relative inversion error was $9.46 \%$, and therefore, the result showed that the SEBAL model had high inversion accuracy.

Land use and land cover affect ET, but there are differences in ET for different vegetation and land cover types. ET can be adequately determined at leaf and plant levels; however, ET is one of the least understood aspects of the hydrologic cycle at large scales. ${ }^{51}$ This is, in part, due to the difficulty associated with assessing ET at a regional scale. ${ }^{52}$ For a given spatial-temporal 
Ning, Gao, and Xu: Effects of land cover change on evapotranspiration in the Yellow River...

condition, there is a close relationship between vegetation index and ET. However, a vegetation index is a reflection of vegetation form, structure, soil regime, and other relevant essential factors, and specific site conditions should be taken into consideration when vegetation indices are used for assessing changes in ET. In this study, we discussed only the linear relationship between ET and surface temperature, and the correlation between FVC and ET. Many additional complicating factors can affect the results.

\section{Conclusions}

From 1986 to 2015, the overall land area increased by $205.81 \mathrm{~km}^{2}$ in the YRD due to sea-land interaction and the influence of sediment deposition by the river. The analysis of land cover change indicated that compared with $1986,3,947.22 \mathrm{~km}^{2}$ of land cover changed in 2015 , accounting for $35.03 \%$ of the total land area in 1986. Different types of land covers were converted in different ways. Despite an increase in the total area, large areas of farmland and grassland were converted into salterns and culture ponds. The diversity of wetland conversion demonstrated the fragility of wetland ecosystems. The development of saline-alkali land was one of the major types of land cover conversion in the area. Overall, land cover conversion occurred mainly from less developed into highly developed land cover types.

There was a close correlation between LST, vegetation coverage, and daily ET. In wetland, saline-alkali land, and coastal beach land cover types, ET decreased with increasing vegetation coverage, revealing the interactions between vegetation and soil. The influence of mixed pixels was an important cause for the existence of inflection points in the curves describing the relationship between FVC and daily ET. As vegetation cover increased, ET exhibited a decreasing trend due to the decrease in LST.

\section{Acknowledgments}

The authors are grateful for the support of the Science and Technology Project of Yantai (No. 2014ZH085), and the Open Research Funding Program of KLGIS (No. KLGIS2014A04). This work was also supported from Aoshan Science and Technology Innovation Program of Qingdao National Laboratory for Marine Science and Technology (2016ASKJ02), Strategic Priority Research Program of the Chinese Academy of Sciences (XDA11020702), Basic Special Program of Ministry of Science and Technology (2014FY210600), Key Research Program of the Chinese Academy of Sciences (KZZD-EW-14).

\section{References}

1. A. Poisson et al., "Thin laser beam wandering and intensity fluctuations method for evapotranspiration measurement," Opt. Laser Technol. 80, 33-40 (2016).

2. H. A. Cleugh et al., "Regional evaporation estimates from flux tower and MODIS satellite data," Remote Sens. Environ. 106(3), 285-304 (2007).

3. L. Jiang et al., "A satellite-based daily actual evapotranspiration estimation algorithm over South Florida," Global Planet. Change 67(1), 62-77 (2009).

4. Q. Mu, M. Zhao, and S. W. Running, "Improvements to a MODIS global terrestrial evapotranspiration algorithm," Remote Sens. Environ. 115(8), 1781-1800 (2011).

5. P. S. Eagleson, "Ecohydrology: Darwinian expression of vegetation form and function," Eos Trans. Am. Geophys. Union 84(35), 345-345 (2002).

6. C. H. B. Priestley and R. J. Taylor, "On the assessment of surface heat flux and evaporation using large-scale parameters," Mon. Weather Rev. 100(2), 81-92 (1972).

7. G. G. Katul et al., "Evapotranspiration: a process driving mass transport and energy exchange in the soil-plant-atmosphere-climate system," Rev. Geophys. 50(3), 185-201 (2012).

8. T. McMahon et al., "Estimating actual, potential, reference crop and pan evaporation using standard meteorological data: a pragmatic synthesis," Hydrol. Earth Syst. Sci. 17(11), 4503-4503 (2013).

9. P. J. Sellers et al., "Modeling the exchanges of energy, water, and carbon between continents and the atmosphere," Science 275(5299), 502-509 (1997). 
Ning, Gao, and Xu: Effects of land cover change on evapotranspiration in the Yellow River...

10. W. J. Shuttleworth, "Putting the "vap' into evaporation," Hydrol. Earth Syst. Sci. 11(1), 210-244 (2007).

11. K. Wang and R. E. Dickinson, "A review of global terrestrial evapotranspiration: observation, modeling, climatology, and climatic variability," Rev. Geophys. 50(2), 93-102 (2012).

12. J. Y. Yang et al., "Water consumption in summer maize and winter wheat cropping system based on SEBAL model in Huang-Huai-Hai Plain, China,” J. Integr. Agric. 14(10), 20652076 (2015).

13. W. G. M. Bastiaanssen et al., "The surface energy balance algorithm for land (SEBAL): part 2 validation," J. Hydrol. 212(98), 801-811 (1998).

14. W. G. M. Bastiaanssen et al., "A remote sensing surface energy balance algorithm for land (SEBAL) - 1. Formulation," J. Hydrol. 212, 198-212 (1998).

15. M. S. Moran et al., "Combining the Penman-Monteith equation with measurements of surface temperature and reflectance to estimate evaporation rates of semiarid grassland," Agric. For. Meteorol. 80(2-4), 87-109 (1996).

16. Z. L. Li et al., "A review of current methodologies for regional evapotranspiration estimation from remotely sensed data," Sensors 9(5), 3801-3853 (2009).

17. Z. Su, "The surface energy balance system (SEBS) for estimation of turbulent heat fluxes," Hydrol. Earth Syst. Sci. 6(1), 85-100 (2002).

18. G. J. Roerink, Z. Su, and M. Menenti, "S-SEBI: a simple remote sensing algorithm to estimate the surface energy balance," Phys. Chem. Earth Part B Hydrol. Oceans Atmos. 25(2), 147-157 (2000).

19. G. B. Senay et al., "Large-scale operational evapotranspiration mapping using remote sensing and weather datasets: modeling and validation," in AGU Fall Meeting Abstracts (2013).

20. W. G. M. Bastiaanssen, "SEBAL-based sensible and latent heat fluxes in the irrigated Gediz Basin, Turkey," J. Hydrol. 229, 87-100 (2000).

21. R. G. Allen, M. Tasumi, and R. Trezza, "Satellite-based energy balance for mapping evapotranspiration with internalized calibration (METRIC)-model," J. Irrig. Drain. Eng. 133(4), 380-394 (2007).

22. R. G. Allen, ASCE Standardized Reference Evapotranspiration Equation, American Society of Civil Engineers (2005).

23. W. G. M. Bastiaanssen and K. Bandara, "Evaporative depletion assessments for irrigated watersheds in Sri Lanka," Irrig. Sci. 21(1), 1-15 (2001).

24. A. Morse et al., "Application of the SEBAL methodology for estimating consumptive use of water and streamflow depletion in the Bear River Basin of Idaho through remote sensing," Final report submitted to the Raytheon Systems Company, Earth Observation System Data and Information system Project, by Idaho Department of Water Resources and University of Idaho (2000).

25. M. M. Hafeez et al., "Estimation of crop water deficit through remote sensing in Central Luzon, Philippines," in IEEE Int. Geoscience and Remote Sensing Symp. (IGARSS '02) (2002).

26. H. Zhang, X. Chen, and Y. Luo, "An overview of ecohydrology of the Yellow River delta wetland," Ecohydrol. Hydrobiol. 16(1), 39-44 (2016).

27. M. D. Blum and H. H. Roberts, "Drowning of the Mississippi Delta due to insufficient sediment supply and global sea-level rise," Nat. Geosci. 2(7), 488-491 (2009).

28. J. P. M. Syvitski et al., "Sinking deltas due to human activities," Nat. Geosci. 2(10), 681-686 (2009).

29. B. S. Cui et al., "Evaluating the ecological performance of wetland restoration in the Yellow River Delta, China," Ecol. Eng. 35(7), 1090-1103 (2009).

30. N. H. Bi, H. J. Wang, and Z. H. Yang, "Recent changes in the erosion-accretion patterns of the active Huanghe (Yellow River) delta lobe caused by human activities," Cont. Shelf Res. 90, 70-78 (2014).

31. M. S. Gao et al., "Vulnerability of eco-hydrological environment in the Yellow River Delta wetland," J. Coastal Res. 30(2), 344-350 (2014).

32. D. X. Kong et al., "Evolution of the Yellow River Delta and its relationship with runoff and sediment load from 1983 to 2011," J. Hydrol. 520, 157-167 (2015). 
Ning, Gao, and Xu: Effects of land cover change on evapotranspiration in the Yellow River...

33. Y. W. Jin et al., "Effects of seashore reclamation activities on the health of wetland ecosystems: a case study in the Yellow River Delta, China," Ocean Coastal Manage. 123, 44-52 (2016).

34. H. J. Wang et al., "Interannual and seasonal variation of the Huanghe (Yellow River) water discharge over the past 50 years: connections to impacts from ENSO events and dams," Global Planet. Change 50(3-4), 212-225 (2006).

35. M. Ottinger et al., "Monitoring land cover dynamics in the Yellow River Delta from 1995 to 2010 based on Landsat 5 TM," Appl. Geogr. 44(4), 53-68 (2013).

36. M. Zhang et al., "Noise reduction and atmospheric correction for coastal applications of Landsat thematic mapper imagery-region 9, Florida West Coast and the keys," Remote Sens. Environ. 70(2), 167-180 (1999).

37. Z. Qin et al., "Mono-window algorithm for retrieving land surface temperature from Landsat TM6 data," Acta Geogr. Sin. 56(4), 456-466 (2001).

38. Y. J. Kaufman and C. Sendra, "Algorithm for automatic atmospheric corrections to visible and near-IR satellite imagery," Int. J. Remote Sens. 9(8), 1357-1381 (1988).

39. S. Liang et al., "An operational atmospheric correction algorithm for Landsat Thematic Mapper imagery over the land," J. Geophys. Res. 102(D14), 17173-17186 (1997).

40. S. Liang, H. Fang, and M. Chen, "Atmospheric correction of Landsat ETM+ land surface imagery-Part I: Methods," IEEE Trans. Geosci. Remote Sens. 39(11), 2490-2498 (2001).

41. S. Liang et al., "Atmospheric correction of Landsat ETM+ land surface imagery: II. Validation and applications," IEEE Trans. Geosci. Remote Sens. 40(12), 2736-2746 (2002).

42. T. Blaschke and J. Strobl, "What's wrong with pixels? Some recent developments interfacing," Remote Sens. GIS 14, 12-17 (2001).

43. Z. Qin et al., "The estimation of land surface emissivity for Landsat TM6," Remote Sens. Land Resour. 3, 28-41 (2004).

44. G. G. Burba, S. B. Verma, and J. Kim, "Surface energy fluxes of Phragmites australis in a prairie wetland," Agric. For. Meteorol. 94(1), 31-51 (1999).

45. R. Waters, R. Allen, and W. G. M. Bastiaanssen, SEBAL (Surface Energy Balance Algorithms for Land) Advanced Training and Users Manual, Version 1.0, pp. 24-25 (2002).

46. M. Zibognon, R. Crago, and A. Suleiman, "Conversion of radiometric to aerodynamic surface temperature with an anisothermal canopy model," Water Resour. Res. 38(6), 3-3-6 (2002).

47. Z. Q. Gao et al., "A coupled remote sensing and the surface energy balance with topography algorithm (SEBTA) to estimate actual evapotranspiration over heterogeneous terrain," Hydrol. Earth Syst. Sci. 15(1), 119-139 (2011).

48. R. D. Jackson et al., "Estimation of daily evapotranspiration from one time-of-day measurements," Agric. Water Manage. 7(1-3), 351-362 (1983).

49. T. W. Owen, T. N. Carlson, and R. R. Gillies, "An assessment of satellite remotely-sensed land cover parameters in quantitatively describing the climatic effect of urbanization," Int. J. Remote Sens. 19(9), 1663-1681 (1998).

50. Z. Ren, "Conversion coefficient of SMAII evaporation of evaporation pan into E-601 pan in China," Q. J. Appl. Meteorol. 13(4), 508-512 (2002).

51. R. R. Nemani and S. W. Running, "Estimation of regional surface resistance to evapotranspiration from NDVI and thermal-IR AVHRR data," J. Appl. Meteorol. 28(4), 276-284 (1989).

52. S. I. Rasool and H. J. Bolle, "ISLSCP: international satellite land surface climatology project," Bull. Am. Meteorol. Soc. 65, 143-144 (1984).

Jicai Ning is an assistant professor at the Yantai Institute of Coastal Zone Research, Chinese Academy of Sciences. He received his BS and MS degrees in geography from Shandong Normal University in 1996 and 2008, respectively, and his PhD degree in cartography and geographic information system from the Institute of Geographic Sciences and Natural Resources Research, Chinese Academy of Sciences, in 2011. His current research interests include coastal zone digitalization and hydrological remote sensing. 
Zhiqiang Gao received his $\mathrm{PhD}$ from the Institute of Remote Sensing Application, Chinese Academy of Sciences, in 1998. He is now a professor with the Yantai Institute of Coastal Zone Research, Chinese Academy of Sciences. His research interests include remote sensing application and model simulation in coastal zone.

Fuxiang $\mathbf{X u}$ is a research assistant with the Yantai Institute of Coastal Zone Research, Chinese Academy of Sciences, Yantai, China. His research interests include environment remote sensing and marine disaster monitoring. 